Mantoux 1/100 (100 T.U.) was carried out. This means that a child was not considered tuberculin-negative until there was no reaction to 100 T.U. at the end of 72 hours. Thereafter on all tuberculin-negative children a diagnostic jelly test was performed during the first week of every month that the child was in the Branch Hospital. After discharge the patient was recalled to the out-patient department for a further jelly test in six to twelve weeks (occasionally a little later).

\section{Results of the Survey}

Of the 209 children who were tuberculin-negative at the beginning it was found possible to follow up 177, and at no time during the period of observation within the hospital or after discharge did any single child develop a tuberculin-positive reaction. It was found impossible to recall 16 other children for their tests after discharge. In order to complete the survey it was necessary to fix a closing date, and at that time there were still nine children in hospital whose average stay was considerably in excess, even at this time, of all other children in the group. Five other children had B.C.G. vaccination during the period under observation. Two children died-one from congestive heart failure following rheumatic carditis and the other after operation for a congenital heart lesion. The average duration of stay in hospital for this group was 58 days.

\section{Discussion}

Rarely a child with a primary tuberculous complex might suddenly and without warning develop a postprimary pulmonary lesion which would rapidly become infective and therefore dangerous. Experience both in and out of hospital has shown that this is an extremely uncommon complication, but nevertheless one which does occur on occasion. It was therefore thought wise to have a monthly $x$-ray examination on each child while in hospital.

Another aspect of the possible spread of tuberculosis in these circumstances is the mobility of the children while in hospital. It was the custom to confine most of them to bed for an initial period of variable duration and to allow more freedom of movement for a longer time each day as they improved Eventually they were permitted to attend the school in the classroom. Even if the child with tuberculosis was kept relatively isolated in bed, other children suffering from other conditions were given complete freedom of movement in the hospital so that they very often played with the tuberculous children We feel that in the circumstances the possibility of other children becoming infected would have been high if the children with tuberculosis were infective, but the results have shown that cross-infection did not seem to occur. The one child with a postprimary pulmonary lesion was kept under very close radiographic supervision, and the response to chemotherapy was so rapid that it seems likely that the infectivity of this particular lesion was extremely low or even non-existent. Eight gastric washings were done at regular intervals, and all proved negative on culture.

The low infectivity of childhood pulmonary tuberculosis is probably due to the small size of the primary foci, to their rapid healing, and to the child's habit of swallowing rather than spitting out his sputum.

Experience has also shown that when one child in a family develops a primary complex from an infection outside the home then it is rare for other children in the same family to develop the disease unless they have been in contact with the original case.
There is, however, another extremely important aspect to the nursing of primary tuberculosis in an open children's ward. It is that the source of infection must be found as quickly as possible, particularly if the infecting individual is likely to be visiting the child. On such visits people tend also to pay attention to other children and might well infect them. In other words, the danger lies not with the child as a patient but with the adults or adolescents coming to see him. It therefore was the practice to ask the parents wishing to visit the children not to do so until a clear chest $x$-ray picture was available. This was arranged on the night of the admission of the child so that parents could be allowed to visit from the following day provided that their chest $x$-ray films were normal. It was also requested that the other relatives would not visit them unless they had normal chest films.

\section{Summary}

Of 374 children admitted to hospital, 209 were tuberculin-negative. Of the latter 177 were tuberculintested after discharge.

These children were nursed in normal association with cases of childhood tuberculosis, and it was found that six or more weeks after discharge 177 were still tuberculin-negative - that is, there was no evidence that they had developed primary tuberculosis while in hospital.

The danger of nursing tuberculous children among other children arises not from the child as a patient but from the adults who may visit the child.

Chest radiography of these adults should be carried out with a minimum loss of time so that visiting to the child is not interfered with.

We are indebted to Professor F. M. B. Allen and the members of the medical staff of the Royal Belfast Hospital for Sick Children for allowing us access to their cases, and to Dr. F. J. W. Miller for much helpful criticism and advice.

\section{FOOD AND INDIGESTION AN INVESTIGATION OF POSSIBLE RELATIONSHIPS} BY

P. H. FRIEDLANDER, M.D., M.R.C.P.

Formerly Leverhulme Scholar, Institute of Clinical Research and Experimental Medicine, Middlesex Hospital, London

I am convinced digestion is the great secret of life.SYDNEY SMITH, 1837.

Many people who have no disease of the gastrointestinal tract find that certain foods disagree with them. Such foods are said to be "indigestible" in the sense that the process of digestion involves discomfort and untoward symptoms. Alvarez and Hinshaw (1935) studied 500 patients and suggested several likely mechanisms whereby foods might disagree with people. The response of the gastric acidity to food has been extensively studied by Rehfuss and his colleagues (Bergeim et al., 1919; Fishback et al., 1919a, 1919b; Smith et al.. 1919; Miller et al., 1919. 1920a, 1920b, 1920c, 1920d), and the gastric emptying-time after various foods by Wilson et al. (1929) and Maile and Scott (1935). However, as the Lancet (1935) pointed out, "It is strange how little relation gastric acidity and gastric emptying often bear to actual digestibility of foods, as evidenced by symptoms of 'indigestion' or their absence." 
Very little experimental work has been published correlating symptoms of indigestion with the possible mechanisms causing them. Brummer and Bundul (1950) studied radiologically 36 dyspeptic patients who had been given food mixed with barium; 12 developed pain. They concluded that the type of food did not influence their results and found no relationship between epigastric pain and gastric or duodenal motility. Brummer and Sysimetsä (1957), using similar methods, found a short-lived decrease in gastric motility in dyspeptic patients after drinking black coffee with cream, which normally caused indigestion. It was not stated, however, whether the patients had symptoms during the tests.

It was decided to study some of the possible organic factors which might be involved in indigestion due to specific foodstuffs, particularly the presence of gastrooesophageal reflux, alterations in gastric motility and acidity, time of transit through the small intestine, distension of the gastro-intestinal tract by masses of food or air, and impairment of gall-bladder function. Correlation of these functions with symptoms at the time of the test would then be made.

\section{Material and Methods}

Dyspeptic patients in whom a barium-meal examination revealed nothing abnormal were studied. Pepticulcer patients were avoided because of the complicating factor that the cause of ulcer pain is unknown. For a similar reason patients with a history suggestive of peptic ulcer were excluded, even in the presence of a normal result of the barium-meal examination. All patients who were selected thought that there was a definite relation between their dyspeptic symptoms and the type of food eaten. A detailed dietary history was taken from 70 such patients ( 37 males and 33 females) whose mean age was 42.9 years (range 18-66), and the following examinations were made on 36 volunteers (19 males and 17 females) from this group. Six ounces (170 g.) of the indigestible food, the nature of which varied with the individual patient, together with $\frac{1}{2} \mathrm{oz}$. (15.5 g.) of barium sulphate ("micropaque" in 13 patients and "microtrast" in the remainder) were eaten by the patient. who had fasted overnight. The gallbladder was outlined by six iopanoic acid tablets taken 12 hours previously.

After the patient had been screened and one $x$-ray film had been taken, the meal was eaten and further films were taken after five minutes, 30 minutes, one hour, two hours, and three hours. In six patients barium sulphate was not given until two hours after the food had been eaten. If the stomach appeared empty at three hours, $4 \frac{1}{2} \mathrm{oz}$. (128 $\mathrm{ml}$.) of diluted barium sulphate solution was given to ensure that the food had not separated from the original barium sulphate and remained behind in the stomach.

In 21 patients gastric acidity was studied at the same time, a radio-opaque Levin tube being passed through the nose into the stomach at the onset of the test before the meal was eaten. The tube was adjusted during the preliminary screening so that the samples of gastric juice obtained came from the body of the stomach: 5-ml. samples of gastric contents were aspirated at 15-minute intervals for three hours.

Between $x$-ray examinations the patient lay propped up on a couch. In six patients the effect of exercise was assessed. the patients walking up 80 steps and back immediately, one hour, and two hours after the meal.
The test was subsequently repeated a few days later in the same patient under similar conditions, except that $6 \mathrm{oz}$. (170 g.) of a control food which did not normally cause dyspeptic symptoms was eaten by the patient. During each test gastro-oesophageal reflux was looked for 30 minutes after food. The emptying of the stomach was estimated by measuring the area of the radioopaque surface of the $x$-ray film at various intervals of time, using squared graph tracing paper, and expressing the results as a percentage of the initial opaque area. Similar measurements were made to estimate gallbladder contraction. All the films were taken in the erect postero-anterior position. The $p \mathrm{H}$ of the gastric contents was measured, using the Cambridge $p \mathrm{H}$ meter and the sealed glass electrode: the free and total acid in the filtered gastric samples were measured by titrating with $\mathrm{N} / 10 \mathrm{NaOH}$, using Töpfer's indicator. Preliminary experiments showed that the presence of barium sulphate did not affect the measurement of gastric acidity by these methods.

\section{Dietary Survey}

Table I shows the foods that disagreed with $15 \%$ or more of the 70 patients. It will be seen that many of the foods have a reputation for being indigestible.

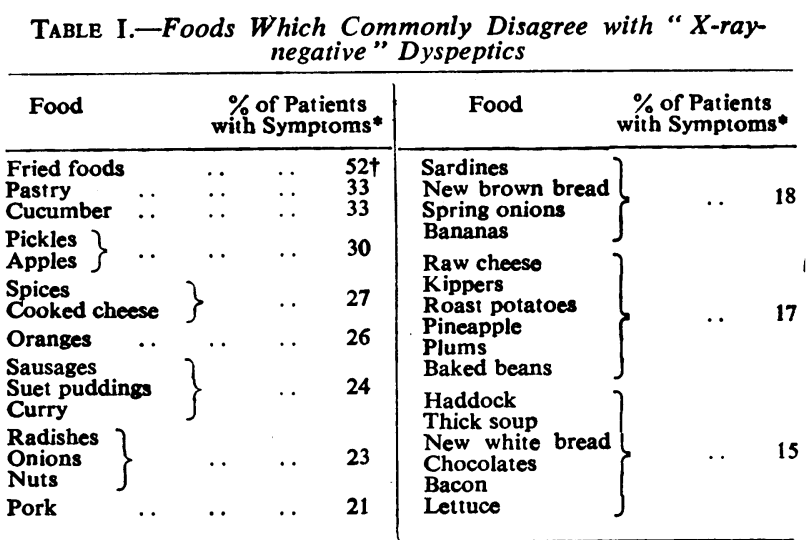

"Excluding " repeating of food," as is frequent with onions, radishes. $+\mathrm{A}$ further $23 \%$ of patients avoided fried foods.

These figures do not include patients who said they avoided certain foods in case these caused indigestion. Thus a further $23 \%$ avoided fried foods for this reason.

\section{Experimental Administration of Indigestible Foods}

Twenty-one different types of indigestible food were given to the 36 patients (Table IJ). Only five bad dyspeptic symptoms during or after the test, and as one of these also had symptoms with the control food she can be excluded (Table III). Of the remaining four patients gastro-oesophageal reflux was present in two, one of whom was also found to have a sliding hiatus hernia. Reflux did not occur during any of the other

TABLE II.-Types of Indigestible Foods Administered to 36

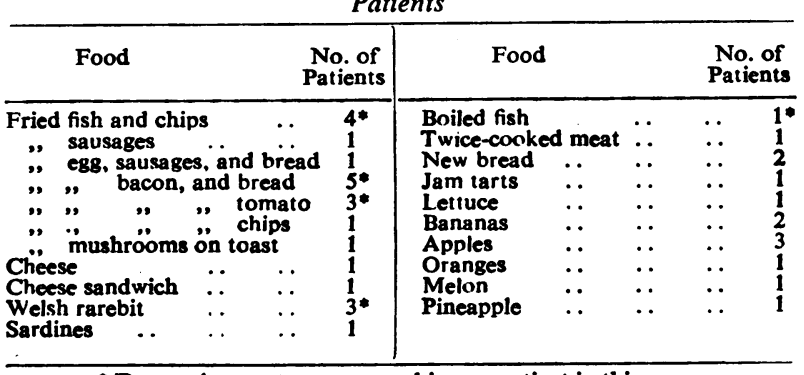

- Dyspeptic symptoms occurred in one patient in this group. 
examinations. The other two patients had pain after eating fried food and are considered in more detail later.

Three more patients had dyspeptic symptoms after eating the control food only, and no symptoms after the indigestible food. Aerophagy with subsequent

TABLE III.-Results of Food Tests

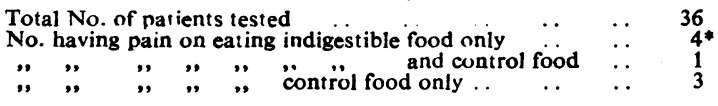

$$
\begin{aligned}
& \text { * } 2 \text { of these patients were shown to have gastro-oesophageal reflux. }
\end{aligned}
$$

distension of the gastro-intestinal tract was surprisingly infrequent, and was never associated with symptoms other than belching. There was no intestinal distension with large opaque masses of food, nor was there any evidence that the food and barium became scparated in the stomach. Intestinal hurry was not present during any of the examinations.

The emptying-times of the stomach were within the expected limits for all patients. Thus after meals, consisting mainly of carbohydrate, the stomach was empty in three hours in every case ; in contrast, emptying was incomplete at three hours in all the patients who ate fried foods. The level of gastric acidity again varied with different foods, but there was much overlap. It was usually less for the first two hours after fricd foods than after non-fatty foods, while carbohydrate foods had only a short-lived stimulating effect. The shapes of the curves obtained by estimating $p H$ and titrating free acid were similar, but it is likely that when food is present the former gives a more reliable estimate (James and Pickering, 1949). In every case the gall-bladder concentrated the dye satisfactorily and contracted after suitable food, though not of course after carbohydrates.

The two patients who had symptoms without gastrooesophageal reflux after eating the indigestible food are dealt with below.

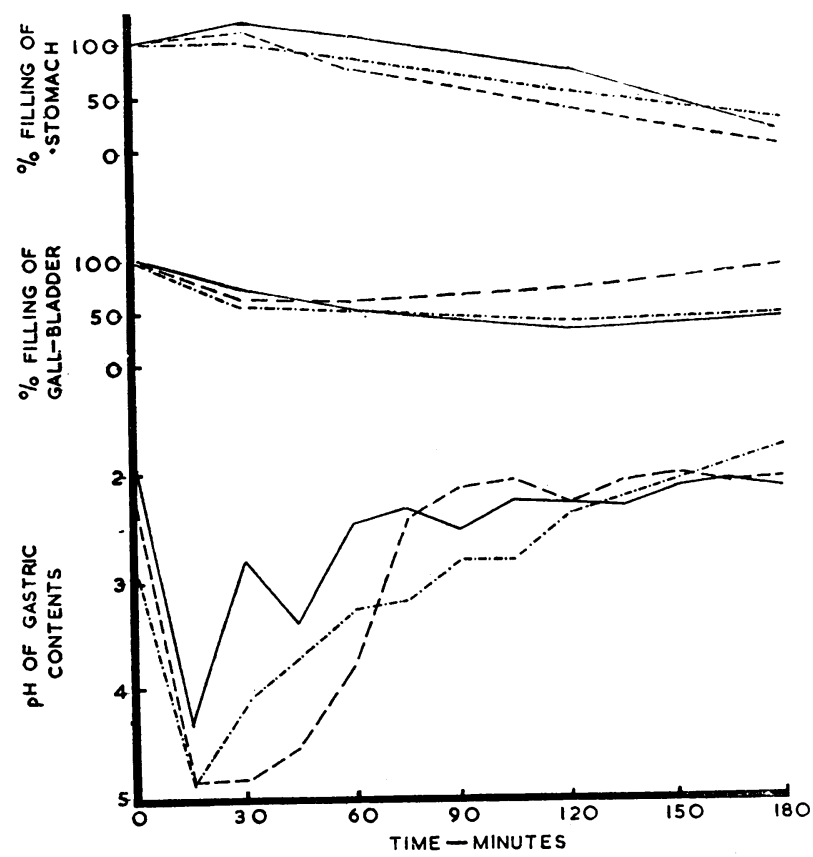

FIG. 1.-Effect of fried food on gastric emptying, gall-bladder contraction, and gastric $\mathrm{pH}$ in Case 1 , compared with a control food and with fried food in eight symptomless patients. In the bottom graph the mean curve after fried food is of four patients bottom graph the mean curve after fried food is of four patients
only. control food. ㄴ..-: Mean curve after fried food, eight patients.

\section{Case 1}

A man aged 44 said that whenever he ate fried food he developed a burning epigastric pain soon afterwards. Half an hour after eating the test meal of fried egg, bacon, bread, and barium he complained of this pain, which lasted two and a quarter hours. In contrast he had no symptoms after eating the control meal of scrambled egg on toast with barium 12 days later.

It will be seen from Fig. 1 that the $p H$ of the gastric contents was greater than two after the meal, and after the first hour was very similar to that of the control meal. It was also of a similar order to the mean curve of four patients who ate the same food without getting symptoms. The rate of stomach-emptying was slower after fried food (stomach $16 \%$ full at three hours) than after the control food (stomach empty at three hours): this would be expected in view of the higher content of fat of the fried food. There was less difference compared with the mean emptying-time of eight patients who ate fried food without symptoms (stomach $27 \%$ full at three hours).

There was a close correlation between contraction of the patient's gall-bladder after fried food and the mean curve of the eight symptomless patients. The control meal caused less-sustained contraction, in keeping with the smaller fat content. Thus this patient's symptoms after eating fried food were not related apparently to the gastric and gall-bladder functions that were measured.

\section{Case 2}

A woman aged 58 complained of attacks of right-sided abdominal pain usually after meals and invariably brought on by fried foods. Twenty minutes after the test meal of fried egg, bacon, tomato, and barium she complained of this pain, which lasted one and a half hours. There was no pain after eating the control meal of poached egg on toast with barium.

No studies of gastric acidity were made. Stomachemptying after the fried food was similar to that after the control meal (Fig. 2). Comparison with the curve of the mean emptying-time of the eight symptomless patients

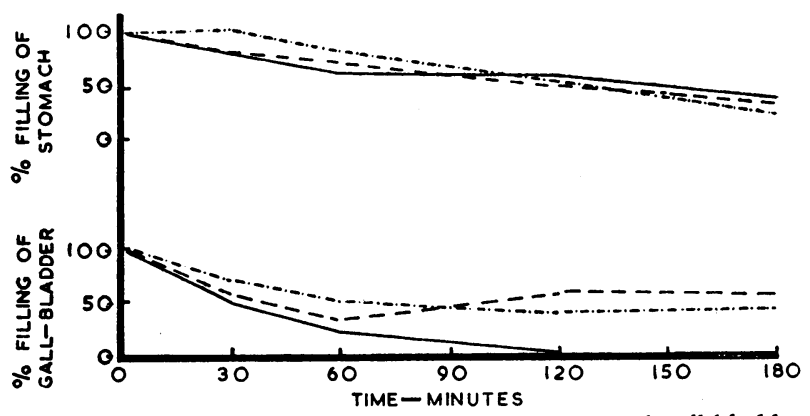

Fig. 2.-Effect of fried food on gastric emptying and gall-hladder contraction in Case 2 compared with a control food and with fried food in eight symptomless patients. Case 2, after fried food - - : Case 2, after control food. -...Mean curve after fried food, eight patients.

again showed close similarity. Gall-bladder emptying was more rapid and complete in the patient after the fried food than after the control food. and was comparable to the mean curve of the eight patients. There was no $x$-ray evidence of associated dilatation of the common bile-duct which would suggest spasm of the sphincter of Oddi at the time of gall-bladder contraction, so it seems unlikely that the pain was related to the contraction of the gall-bladder.

\section{Discussion}

It is clear from these results that in spite of the belief of all the patients studied that certain specific foods brought on their symptoms, this effect occurred in only four out of the 36 patients when some of these foods were tested, and gastro-oesophageal reflux was present in two of these, and may be presumed to account for their symptoms. In the other two patients no 
mechanism for their pain was demonstrated. This does not necessarily mean that the symptoms have a psychological basis, but they may well be due to the inadequacy of the methods used to detect abnormal functioning of the gastro-intestinal tract. However, the occurrence of pain in one patient with both the control and the indigestible foods, and in three others with the control food alone, suggests that the actual composition of the food is not responsible for these patients' indigestion.

These results are surprising. Foods have long been held to be a cause of dyspeptic symptoms. Brinton (1864) suggested a classification of dyspepsia " according to that alimentary constituent, the failure of which to be digested provokes their symptoms." Alvarez and Hinshaw (1935) considered as possible causes of distress after the eating of certain foods, allergy, druglike substances in the food causing bowel irritation and altered gastro-intestinal peristalsis, and the bulk effect of cellulose-containing foods. They pointed out that a food which is tasted during belching or regurgitation, such as onions, is more likely to be blamed than one which is not: accordingly, such foods were not used in the present tests, though this is unlikely to be the explanation of the failure of nearly all the patients to get symptoms.

Previous workers have shown that various foodstuffs can alter gastric motility. Thus Wirts et al. (1954) showed that tea appeared to stimulate gastric motility and increase the rate of emptying compared with water. Brummer and Sysimetsä (1957) compared the effect of black coffee and black coffee with cream on gastric motility, studied radiologically in dyspeptic patients and controls. Most of the dyspeptic patients showed an immediate, short-lived decrease in gastric motility after coffee with cream, not seen with the control patients. No mention was made of correlation of these findings with symptoms, but in any case the authors felt that these were not the cause of the dyspeptic symptoms. Siurala et al. (1953) studied $130 x$-ray-negative dyspeptic and 56 non-dyspeptic patients, but were unable to find any relationship between $x$-ray changes in the stomach and acid secretion and the patients' discomfort. However, they felt that their methods were inadequate to rule out functional disorders of the stomach as a cause of distress related to meals.

The present results are in agreement with those of Brummer and Bundul (1950) previously mentioned, though a third of their patients developed pain during the tests with indigestible foods. The patients in the present series were selected because they were subject to dyspepsia and were certain that this occurred after some but not all foods. Thus a bias would be expected in favour of their developing symptoms. It might be thought that, as with ulcer pain induced by the administration of intragastric hydrochloric acid, symptoms could be reproduced only during an active bout of dyspepsia. But the dyspeptic symptoms attributed to specific foods by these patients were said to occur whenever these foods were eaten and were not cyclical, as is usual with ulcer patients.

It is possible that the abnormal experimental conditions, such as the eating of food mixed with barium in unusual surroundings or the presence of a stomachtube in some patients, might invalidate the results: but these conditions would be expected to accentuate rather than diminish symptoms, particularly if thesse were psychological in origin. That the stomach-tube plays a part is unlikely, as symptoms occurred in two patients with a tube and two without. Further confirmatory evidence that the failure to produce symptoms was not due to experimental conditions comes from 14 of the patients who subsequently ate the indigestible food at home without symptoms. It might also be argued that patients forget after a time which foods do in fact upset them. However, symptoms had been present in 10 of the patients for less than two years, but only one of these had symptoms during the test.

In case barium sulphate made the food more digestible the barium was not given until two hours after food in six patients, none of whom developed symptoms. The amount of food eaten might affect the incidence of symptoms, but this was standardized and corresponded so far as was possible to an amount normally eaten, such as a fried egg, two rashers of bacon, and one slice of fried bread. Speed of eating might be another factor, but is unfortunately subjective. Eighteen patients said they ate quicker than average, 10 slower, and only eight at average speed. Two of the patients with symptoms fell in the quick group. and two in the average group. It seems unlikely. therefore, that this plays a significant part in the production of their symptoms. Mixtures of food rather than single foods might be the cause of indigestion attributed to a particular food, but this would be an extremely difficult hypothesis to test.

Sitting down for three hours after a meal is another possible explanation for the failure of the patients to develop indigestion, but only one of the six patients who were exercised after a meal developed symptoms. In the two patients who developed symptoms which have not been explained there was no evidence of allergy. Neither was this a likely explanation for the symptoms complained of by the patients: a personal or family history of allergic disorders was given by only four of the patients, none of whom developed dyspeptic symptoms during the tests.

The most likely explanation is that in these patients with non-ulcer dyspepsia the actual nature of the food is not an important factor in the production of their dyspeptic symptoms. There are so many well-known indigestible foods that almost any bout of indigestion. whatever the cause, is likely to have been preceded by the eating of one of these foods during the previous few days. This particular food is then wrongly held responsible by the patient for the symptoms. Perhaps Mark Twain gave good advice when he said that the secret of success in life is to eat whatever you like and let the food fight it out inside.

\section{Summary}

A dietary survey of 70 patients with non-ulcer dyspepsia who attributed dyspeptic symptoms to certain specific foods was made. Thirty-six of these ate an "indigestible" food mixed with barium sulphate and were radiographed at intervals for three hours: the gallbladders of these patients were outlined with iopanoic acid. Simultaneous studies of gastric acidity were also made in 21 . The studies were subsequently repeated, a non-indigestible food being used as a control.

An attempt was made to correlate the patients symptoms during the tests with the findings from these investigations. Only four patients developed symptoms with the indigestible food: gastro-oesophageal reflux was present in two, but no mechanism was apparent in the other two. One other patient had symptoms with both the indigestible and the control food, and three with the control food alone. 
It is concluded that in these patients the composition of the food did not play an important part in the causation of their dyspeptic symptoms.

My thanks are due to Dr. H. L. Marriott for his encouragement and advice; to the physicians of the Middlesex Hospital for permission to study patients under their care ; to Mrs. M. Fyfe for technical help ; to Miss E. Wilkinson Hughes, senior dietitian, the Middlesex Hospital; and to Mr. T. E. Cowan for Figs. 1 and 2.

\section{REFERENCES}

Alvarez, W. C., and Hinshaw, H. C. (1935). J. Amer. med. Ass., 101, 2053 .

Bergeim, O., Evvard. J. M., Rehfuss, M. E., and Hawk, P. B. (1919). Amer. J. Physiol., 48, 411 .

Brinton, $W$. (1864). Lectures on the Diseases of the Stomach 2nd ed., p. 310 Churchill, London.

Brummer, P., and Bundul, A. (1950). Ann. Med. intern. Fenn. 39. 73.

and Sysimetsï, E. (1957). Acta med. scand., 159, 141

ishback, H. R., Smith, C. A., Bergeim, O., Lichtenhaeler, R. A., Rehfuss, M. E., and Hawk, P. B. (1919a). Amer. J. Physiol., 49, 174.

49. 222.

James, A H., and Pickering, G. W. (1949). Clin. Sci.. 8, 181.

Luncet, 1935, 1. 35

Maile. W. C. D., and Scott, K. J. L. (1935). Lancet, 1, 21, 1500. Miller, R. J., Bergheim, O., Rehfuss, M. E., and Hawk, P. B. (1920a). Amer. J. Physiol., 52, 28

(1920b)., Ibid., 53, 65.

Fowler, H. L., Bergeim, O., Rehfuss, M. E., and Hawk, P B. (1919). Ibid., 49, 254 .

$二=-(1920 \mathrm{c})$. Ibid., 51, 332.

Siurala, M.. Lehtinen, M., and Setälä, K. (1953). Acta med. scand., 147, 26).

Smith, C. A., Fishback, H. R., Bergeim, O., Rehfuss, M. E., and Hawk, P. B. (1919). Amer. J. Physiol.. 49, 204.

Wilson, M. J., Dickson, W. H., and Singleton, A. C. (1929). Arch. intern. Med., 44, 787.

Wirts, C. W., Rehfuss, M. E., Snape, W. J., and Swenson, P. C. (1954). J. Amer. med. Ass., 155, 725.

\section{Medical Memoranda}

\section{Suicidal Attempt by Imipramine Overdosage}

Imipramine ("tofranil ") is an iminodibenzyl derivative which has recently been introduced for the treatment of depressive states. While its value in these conditions is still under investigation there have been reports of some side effects, and these include dryness of the mouth, giddiness, tachycardia, disturbances of accommodation, fine tremor, and hypotension (Kuhn, 1957 ; Kielholz and Battegay, 1958). There has been only one report (Moll, 1959) of the effects following the ingestion of a large quantity, and accordingly it may be of interest to record the following case.

\section{CAse Report}

A woman aged 29, a trained nurse, suffering from a recurrent depressive illness and previously treated with electric convulsion therapy, had been taking imipramine. 25 mg. t.d.s., for 16 days. At 10 p.m. on February 19, 1959, she took a total of $1.500 \mathrm{mg}$. of the drug. with suicidal intent, and retired to bed. For the first three-quarters of an hour she experiencd no symptoms, and after this she apparently went to sleep. She has no recollection of any dreaming. and woke at 6.30 a.m. the next day in an agitated state, with gross involuntary movements of all her limbs, head. and neck, which she described as being just like those of a fit and of a violent and terrifying nature. She remained in this state for some time, being unable to shout for help. Eventually her mother brought her a morning cup of tea, and, seeing the gross movements, asked what was wrong. The patient was unable to tell her what had occurred, and was onfy able to mutter meaningless noises. She was, however, able to gesture towards the empty bottle of tablets.
During this period of involuntary movements she was quite conscious and clearly recollected what was happening, even though the movements were completely uncontrollable. She knew what she wanted to say, but was unable to articulate the words. After about one hour the movements in the limbs gradually diminished, those in the right leg being the last to subside. She had no beadache, no difficulties with her vision, and no pain. There were paraesthesiae ("pins and needles") of the whole of her body, arms, and legs, and these continued for ahout one hour after the gross involuntary movements had ceased.

She was taken to the Bristol Royal Infirmary, where her stomach was washed out and the blood-pressure recorded as $100 / 70$. Her admission to Barrow Hospital was then arranged.

On admission, at 10 a.m. on February 20 . the most prominent feature was that of a state of over-alertness. Her face showed marked pallor, and the general appearance was that of anxiety. She was restless; she glanced rapidly around the room, and had a fine, rapid tremor of the hands. Her speech was jerky. rapid. and slurred. She had tachycardia (130 beats a minute) and the blood-pressure had ricen to $130 / 90$. Her temperature was $99.6^{\circ} \mathrm{F}$. $\left(37.55^{\circ} \mathrm{C}\right.$.). There was slight difficulty at first on passing urine, which was found to contain ketone bodies (Rothera's test). Her mouth was dry; she had a considerable thirst and no appetite. There was some increase of muscular tone of the cogwheel variety, tendon reflexes were normal, plantar responses were flexor, and objective sensory tests were normal. Her pupils reacted normally to light, but initially there was slight difficulty in accommodation. Her mental state did not appear to be impaired, and she could remember quite clearly the events of the past few hours. She could repeat eight digits forward and six backwards correctly. Her mood was one of depression and marked misery, but without any remorse or guilt because of her suicidal attempt.

Investigations.-Electroencephalograms taken on admission showed a record which was outside the normal limits and had a marked excess of slow activity (this could have been due to either imipramine-induced drowsiness or previous treatment with E.C.T.). Electrocardiograms showed simple tachycardia (rate 120); $\mathrm{T}$ wave flattened in lead II and inverted in lead III. Blood count was normal, with eosinophils $110 /$ c.mm.

Progress.-During the next three days there was a gradual improvement in her condition without any special treatment being given. Mentally she remained depressed, and in view of this she was eventually given further E.C.T. The blondpressure remained stationary, the fever settled, and the tachycardia disappeared.

\section{COMMENT}

The interesting features of this case are (1) the gross involuntary movements and dysarthria which occurred a few hours after taking the drug: (2) the lack of marked change of blood-pressure even though the drug has a methonium type of side chain; (3) the paraesthesiae and general atropine-like effects of the drug.

Three salient points are the inability of the drug to prevent a suicidal attempt while being used therapeutically (the dosage of $25 \mathrm{mg}$. t.d.s. is, however, smaller than the optimum recommended by the makers); the lack of improvement of depression following gross overdose ; and the relative safety of the drug in this case when it was taken with suicidal intent.

$$
\begin{aligned}
& \text { N. P. Lancaster, M.D., D.P.M., } \\
& \text { A. R. Foster, M.B., B.Sc., D.P.M., } \\
& \text { Barrow Hospital, Bristol. }
\end{aligned}
$$

REFERENCES

Kielholz, P., and Battegay, R. (1958). Schweiz. med. Wschr., 88. 763 .

Kuhn. R (1957). Ibid.. 87, 1135

Moll, A. E. (1959). Canad. psychiat. Ass. J., 4, s. 64. 